\title{
Spray-drying technique to prepare innovative nanoparticulated formulations for drug administration: a brief overview
}

\author{
S.S. Guterres* \\ Programa de Pós-Graduação em Ciências Farmacêuticas, \\ Faculdade de Farmácia, Universidade Federal do Rio Grande do Sul, \\ Av Ipiranga, 2752, Porto Alegre, 90610-000, RS, Brazil \\ R. C. R. Beck \\ Departamento de Farmácia Industrial, Centro de Ciências da Saúde, \\ Universidade Federal de Santa Maria, Av. Roraima, 1000, Santa Maria, 97105-900, RS, Brazil
}

A. R. Pohlmann

Departamento de Química Orgânica, Universidade Federal do Rio Grande do Sul, PBOX 15003, Porto Alegre, 91501-970, RS, Brazil (Received on 15 July, 2008)

\begin{abstract}
Polymeric nanoparticle systems (nanocapsules and nanospheres) present potential applications as drug delivery systems. Nevertheless, their full applications have not been exploited due to their limited shelf life when stored in aqueous medium. Drying polymeric nanoparticles using spray-drying represents a promising platform to improve the physicochemical stability of formulations and/or to control the release of hydrophilic and lipophilic drugs. This article presents a brief overview of the most recent and ongoing research in the use of spray-drying process to prepare and/or to dry polymeric nanoparticles formulations intended for drug administration.
\end{abstract}

Keywords: microparticles; nanocapsules; nanospheres; spray-drying

\section{INTRODUCTION}

Spray-drying is a common technique used in pharmaceuticals to produce a dry powder from a liquid phase [1]. This technique has also been employed as a microencapsulation method because it can be adapted to the development of different systems, microspheres or microcapsules, depending on the initial aqueous formulation, a solution, a suspension or an emulsion [2]. Another application is its use as a preservation method, increasing the storage stability due to the water elimination.

Nanoparticle, submicronic colloidal carriers, is a general name to describe nanocapsules and nanospheres. Nanocapsules correspond to a polymeric wall enveloping an oil core, while the nanospheres consist of a polymeric matrix [3]. Nanoparticles have been extensively studied over the last years in order to control the drug release, to increase the drug selectivity and effectiveness, to improve drug bioavailability and decrease the drug toxicity [4,5]. Nevertheless, the full applications of polymeric nanoparticles have not been exploited due to the lack of stability of formulations when conserved in aqueous medium for a long period [6]. During the storage, microbiological growth, polymer hydrolysis and physicochemical instability as a consequence of particle aggregation can take place [7]. According to Tewa-Tagne and co-workers, efforts to develop more stable nanoparticle formulations have been unsuccessfully carry out for many years [8]. The type and the concentration of surfactants in the formulations have been varied, but the results shown good stability only in the short-term $[9,10]$. On the other hand, the incorporation of nanoparticles in solid dosage forms resulted in phase separation after the addition of different polymeric binders to aque-

*Electronic address: silvia.guterres@ufrgs.br ous suspensions of nanoparticles [11]. So, the development of an effective technique to improve the shelf life of nanoparticles is a requirement.

Microparticles are generally composed by polymeric materials and present advantages such as a rapid and one step production, ready distribution on a large surface of the body, more constant plasma levels, higher accuracy in reproducibility dose-by dose, less decrease in bioavailability and minor risk of toxicity due to the dose dumping $[12,13]$. A modern microparticle formulation should be able to provide a controlled and well-defined drug release pattern.

In the last years our research group and others have been involved in the study of the potential of the spray drying technique to stabilize polymeric nanoparticle aqueous suspensions converting them into powders, as well as to prepare innovative nanocoated-microparticles to control the drug release. So, this article presents a brief overview of most recent and ongoing research in the use of spray-drying process to prepare and/or to dry polymeric nanoparticles formulations intended for drug administration.

\section{DRYING POLYMERIC NANOPARTICLE SUSPENSIONS}

Aiming to overcome the instability of nanocapsules, our group proposed for the first time in 2000 the use of the spraydrying technique to convert nanocapsule or nanospheres aqueous formulations into powders [14]. So, we reported oral solid forms containing diclofenac-loaded nanoparticles, prepared using colloidal silicon dioxide (Aerosil ${ }^{R}$ 200) as drying adjuvant (Figure 1A). The scanning electron microscopy analysis of spray-dried powders showed spherical microparticles, which presented the nanoparticles on their surface. The powders obtained from the nanocapsule suspensions showed nanostructures adsorbed on the microparticles, with similar 
particle sizes $(200 \mathrm{~nm})$ than those determined by PCS in the suspensions before dehydration process [14].

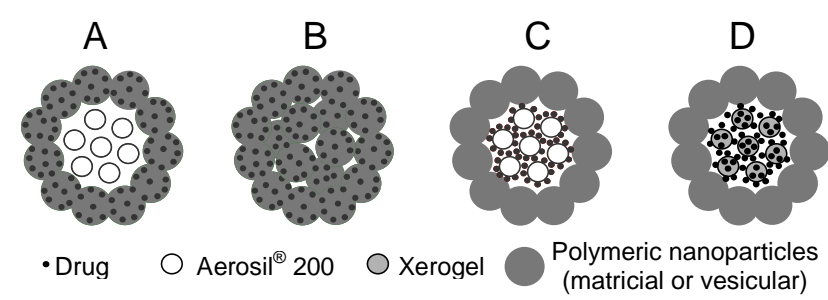

FIG. 1: Illustrative representation of the architecture of different nanostructured microparticles obtained either by sequential assembly of silica and polymeric nanoparticles or by drying polymeric nanoparticles: type A is prepared by drying the drug-loaded polymeric nanoparticles with colloidal silicon dioxide; type B is obtained by drying the polymeric nanoparticles using water soluble materials; and type $C$ and $D$ are prepared by coating the drug-loaded Aerosil ${ }^{\circledR}$ 200 or xerogel, respectively, with polymeric nanoparticles

On the other hand, the micro-powders prepared from the nanosphere suspensions presented a reduction in the particle size which decreased from $200 \mathrm{~nm}$ to $60-90 \mathrm{~nm}$ after drying $[15,16]$. The polymeric nanoparticles used to coat the inorganic microparticles can be prepared by nanoprecipitation or interfacial deposition of pre-formed polymers [17], as well as by emulsification-diffusion technique [18]. Regarding the biological effects, after oral administration in rats, the diclofenac-loaded nanocapsule spray-dried powders dispersed in water were valuable for reducing the gastrointestinal irritant effect of the non-steroidal anti-inflammatory drug [19]. In parallel, a pharmacokinetic study in rats was also conducted, showing a complete oral absorption of the drug from spray-dried powders dispersed in water [19].

In addition, those diclofenac-loaded nanoparticle spraydried powders have been investigated after 14 months of storage at ambient temperature. The powders showed higher chemical stability than the drug-loaded nanocapsule suspensions. Our study showed that besides the nature of the formulation, suspension or powder, the decrease in the drug content is dependent on the type and concentration of the surfactant system. An accelerate stability study carried out under UVC light exposition followed by mass spectrometry analysis demonstrated that 2-(2',6'-dichlorophenyl)aminobenzyl alcohol and N-(2',6'-dichlorophenyl)anthranilylaldehyde were the diclofenac degradation products [20].

Nanocapsules and nanospheres containing an antiinflammatory drug were freeze-dried after addition of colloidal silicon dioxide to obtain intact dried nanoparticles [21]. The micro-powder surfaces presented a homogeneous nanocoating and satisfactory biological effect (gastrointestinal tolerance). However, in spite these promising results, the freeze-drying technique is highly expensive and reserved for products with high added value [22]. So, we continued our study in the use of spray-drying to dry the polymeric nanoparticle suspensions. In the case of the nanocapsule spray-dried powders, the oil concentration in the suspension presented an important influence on the homogeneous recovering of the particles. The powders prepared using low oil concentration showed two patterns of nanoparticles on the microparticle surface [23].
Indeed, based on those results we acquired the knowledge needed for the design of homogeneous nanocoating surfaces. The morphologic control of the micro-powder coating is determined by the use of either polymeric spheres or vesicular nanoparticles. These studies showed the different behavior of polymeric nanocapsules and nanospheres in the preparation of these organic-inorganic microparticles [15,16,19,23]. The nanosphere suspension (polymeric matrix) or the nanocapsule suspension (vesicular nanostructure) led to microparticles presenting different and homogeneous nanocoating after the drying process [16]. It is important to note that considering this drying strategy the drug is encapsulated in the polymeric nanoparticles. In spite the evident advantages of the spray-drying in the presence of silicon dioxide as a strategy to dry the aqueous suspensions, the interactions between the polymeric nanoparticles and the silicon dioxide had not been investigated.

Viewing to understand what kind of interactions takes place, Tewa-Tagne and co-workers demonstrated that the interactions occurring in the feed are directed by hydrogen bounds and they were more sensitive to the silica concentration than that of nanocapsules [8]. SEM analyses of the powders showed spherical separated microparticles formed by the association of nanocapsules and silica when they are mixed at adequate concentrations in the feed before spraydrying. On the other hand, fused agglomerated particles presenting nanocapsules at their surface, characterized by irregular shapes and a strong adhesiveness were prepared when the silica concentration was not sufficient.

More recently, the effects of formulations and spray-drying process variables on the powders properties has been studied in order to optimize the process [22]. Due to the high numbers of parameters involved in the spray-drying process, particular attention is required in the process optimization. Responses such as temperature, moisture content, operation yield, particle size and particle densities are useful to determine the optimal operational conditions. In the particular case of drying nanocapsules using silicon dioxide as an auxiliary agent, the concentrations of both determined the powder characteristics. Besides silicon dioxide, soluble supports such as lactose, PVP-K30 and mannitol can also be employed to dry nanocapsules [24]. Using nanocapsules at a concentration of $1 \%(\mathrm{w} / \mathrm{v})$ and lactose at $10 \%(\mathrm{w} / \mathrm{v})$, the powder had adequate morphology and ease reconstitution in water (Figure 1B). Focusing on the size distribution after reconstitution, satisfactory result has been observed using mannitol and PVP-K30 both at $10 \%$ $(\mathrm{w} / \mathrm{v})$.

\section{PREPARING INNOVATIVE NANOPARTICLE-COATED MICROPARTICLES}

As described above, we have developed a method to dry nanoparticulated aqueous suspensions by spray-drying in order to obtain dried nanoparticle formulations. Actually, the powders consisted of microparticles of silicon dioxide coated by polymeric nanoparticles (containing a drug) (Figure 1C). Besides the higher stability compared to the original nanoparticle suspension, these powders have the ability to control and sustained the drug release. Melatonin-loaded nanocapsule spray-dried powder improved the physical stability of the 
formulation and controlled the drug release profile in comparison with the pure drug [25]. Moreover, a monoexponential model described the release profile and the drug release was governed by swelling, relaxation and dissolution of the polymer.

Indeed, coating techniques are largely employed in order to control the drug release from dosage forms for oral administration, as well as to protect the drug from inactivation or the gastrointestinal mucosa against drug damage. In general coating processes are carried out on single unit dosage forms, as tablets or capsules, after their production [26]. Several reports in the literature show that the coating of particles presents more advantages compared to the coating of unit dosage forms $[27,28]$. These advantages are given by the more reproducible gastrointestinal transport, higher bioavailability, more uniformly spread out in the gastrointestinal tract and reduction of the local irritation. The main useful methods in particle coating are air suspension (Wurster process, fluidbed dryer), centrifugation, spray drying, coacervation (aqueous phase separation) and interfacial polymerization [26].

Taking into account that coating systems using organic solvents need to be avoided due to safety and economic disadvantages and that the polymeric nanoparticles are aqueous dispersions, we considered that the latter could be also useful to coat the microparticles to control the drug release. In this way, new nanoparticle-coated drug-loaded organic-inorganic microparticles using the spray-drying technique were proposed (Figure 1C). In 2004, we reported for the first time the preparation of spray-dried nanoparticle-coated microparticles using diclofenac and unloaded nanoparticles (nanospheres or nanocapsules) prepared with Eudragit $\mathrm{S} 100^{\circledR}$ as a coating material [29]. The work showed the preparation of these microparticles using a one-step and a two-step method. In the one-step method the microparticles were prepared by the addition of the drug and silicon dioxide directly into the nanoparticle suspension before the spray-drying. On the other hand, using the two-step method, an organic-inorganic core was previously prepared by mixing the drug and silicon dioxide in acetone followed by solvent evaporation under reduced pressure. This core was redispersed in the nanoparticle suspension before the drying process. All formulations showed the presence of nanostructures on their surface forming a covering layer which particle diameters were in accordance with the original suspension. When the diclofenac (sodium salt) was employed as hydrophilic model, the powders prepared in two steps (core previously prepared) showed satisfactory gastroresistance. The use of diclofenac (acid form) as hydrophobic model also conducted to powders presenting good gastroresistance using triacetin as a plasticizer in the nanocapsule formulations [30]. The type of the coating layer (nanospheres or nanocapsules) had also an important influence on the protective efficiency against gastrointestinal injury after oral administration of diclofenac, which gastrointestinal side-effects, such as irritation, ulceration and mucosal damage are well known. Following oral administration in rats, nanocapsule-coated diclofenac-loaded microparticles demonstrated a significant protective effect of the gastrointestinal mucosa against ulceration [30].

The morphological studies showed that these nanoparticlecoated drug-loaded microparticles presented a decrease in the powder surface area compared to the powders before coating independently on the preparation method (one-step or two-steps) or the drug model (diclofenac salt or acid) [31]. The decrease in the surface area was also dependent on the type of polymeric nanoparticle used as coating material. Nanocapsule-coated microparticles showed a higher decrease in the surface area, as well as in the pore size distribution in the mesoporous region, compared to the nanospherecoated microparticles [30,31]. The effects of spray-drying process variables (inlet temperature and feeding spray rate) on the physicochemical properties of the powders were also studied in order to optimize the coating process. They were dependent on the type of the coating material. The control of these processing variables allowed obtaining nanosphere or nanocapsule-coated microparticles with satisfactory yields, particle sizes, encapsulation efficiencies and low water contents [30].

The use of another nanostructured suspension obtained by the dispersion of Eudragit $\mathrm{S} 100^{\mathrm{R}}$ in phosphate buffer $\mathrm{pH} 7.4$ $(50-400 \mathrm{~nm})$ instead of nanocapsule or nanosphere suspensions to prepare nanoparticle-coated microparticles were also reported by our research group [32]. These spray-dried microparticles present similar advantages to nanocapsule and nanosphere-coated microparticles considering the gastrointestinal protection against diclofenac mucosal damage and control of drug release. The major advantage of this microparticulated system is the absence of organic solvent either in the preparation of the polymeric nanostructure suspension or in the coating step.

The efficient control of drug release from nanoparticlecoated microparticles was also showed by an in vitro drug transport study across Caco-2 cell monolayers [33]. Nanoparticle-coated dexamethasone-loaded microparticles were prepared and showed efficient coating by the polymeric nanostructures as observed by SEM and atomic force microscopy (Figures 2 and 3). In accordance with the in vitro drug release studies at $\mathrm{pH} 7.4$, nanocapsule-coated microparticles presented lower permeability coefficient values across this human intestinal cell line compared to the free dexamethasone solution, mainly in the presence of a plasticizer in the microparticle formulation. This lower permeability across the cell layers is explained by the more internal localization of the drug in this formulation as confirmed by the mathematical modeling of the drug release data [33]. Furthermore, cytotoxicity studies showed that the nanoparticle-coated microparticles are non-toxic to the membranes of Caco- 2 cells. This recent study reinforced that nanocapsule-coated microparticles represent a promising platform for the development of controlled oral drug delivery systems.

Regarding the mechanism of drug release from these nanoparticle-coated microparticles, Domingues and coworkers showed a controlled release of indomethacin, a nonsteroidal anti-inflammatory drug, from nanocapsule-coated microparticles prepared in one step compared to the pure drug [34]. The drug release profiles fit to the monoexponential equation and the Korsmeyer-Peppas model, which allowed the proposition of a non-Fickian release mechanism dependent on the nanocapsule-coated microparticle desagglomeration [34].

Recently, we proposed the use of silica xerogel as core material considering that its use instead of Aerosil ${ }^{\circledR} 200$ to encapsulate drugs could have the advantage of delaying 


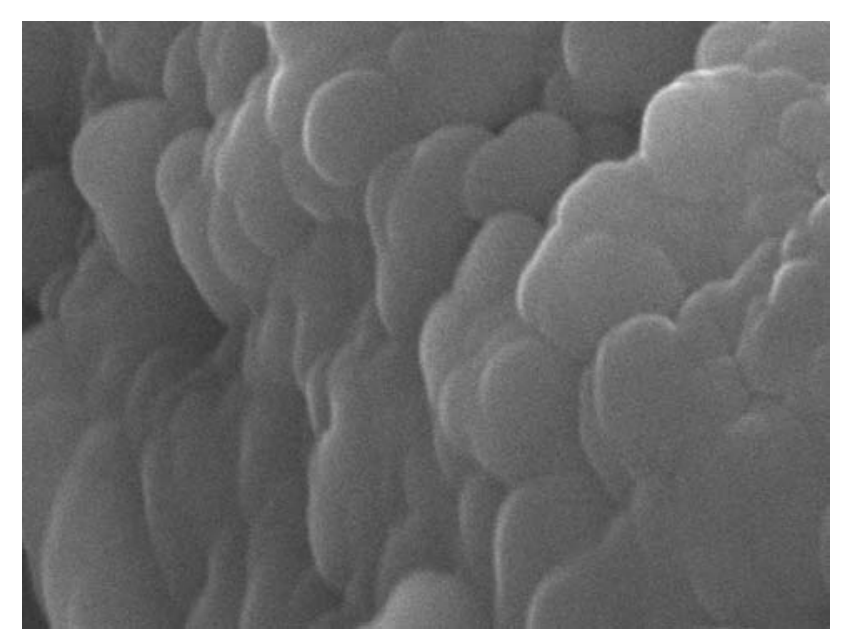

FIG. 2: SEM micrographs of nanocapsule-coated dexamethasoneloaded microparticles obtained by spray-drying (photo width $=2.93$ $\mu \mathrm{m})$.

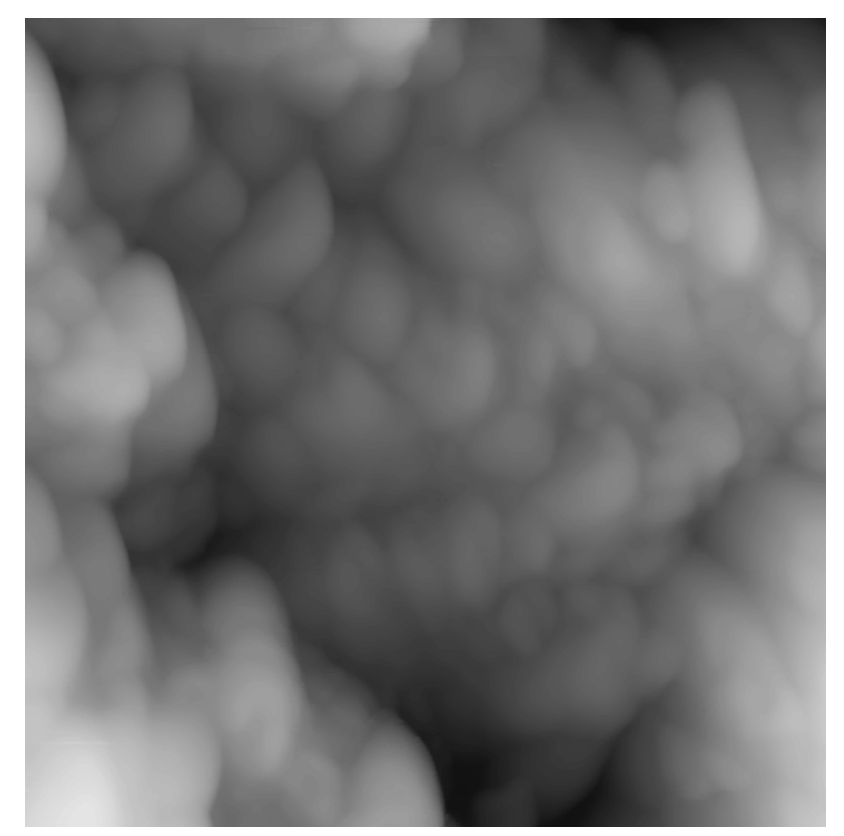

FIG. 3: AFM image of nanocapsule-coated dexamethasone-loaded microparticles ( $1 \mu \mathrm{m} \times 1 \mu \mathrm{m}$ image).

the drug release because the drug is also encapsulated in the mesoporous besides its encapsulation in the xerogel macropores [35]. Moreover, to diminish the burst release of the drug from the xerogel the particles have been coated with polymeric nanoparticles (Figure 1D). The silica xerogel has been prepared in situ in the presence of the drug, sodium diclofenac, used as hydrophilic model. Then, the powder has been coated with polymeric nanocapsules by spray-drying. The drug release experiments showed the gastroresistance and the efficacy of the new system in reducing the burst release and in sustaining the sodium diclofenac dissolution profile. The nanocapsule-coated drug-loaded xerogel microparticles showed potential use for controlling the release of hy- drophilic drugs.

Table 1 summarizes the nanostructured microparticles prepared by drying polymeric nanoparticles in order to obtain stable products and/or controlled release formulations. The different systems (Figure 1A-D) are able to encapsulate and control the release of drugs which characters are hydrophilic or lipophilic depending on its localization in the phases of microparticles.

\section{CONCLUSION}

The nanostructured microparticles that were reviewed in this article are useful to encapsulate either lipophilic or hydrophilic drugs. In addition, drying polymeric nanoparticles using spray-drying technique is a promising platform to improve the physicochemical stability of formulations and/or to control the release of drugs. Finally, the use of different materials leads to well defined complex architectures and determines the routes of drug administration.

\section{ACKNOWLEDGMENTS}

Rede Nanocosméticos CNPq/MCT, FINEP, CNPq/Brasil and C. M. Lehr from Department of Biopharmaceutics and Pharmaceutical Technology/Saarland University (Germany) for the AFM analysis. 
Table 1. Nanostructured microparticles: composition, preparation technique, model of structure and main results

\begin{tabular}{|c|c|c|c|c|}
\hline Polymeric nanoparticles & $\begin{array}{c}\text { Drying } \\
\text { adjuvant/technique }\end{array}$ & $\begin{array}{c}\text { Type of } \\
\text { nanostructured } \\
\text { microparticles }\end{array}$ & Results & Ref \\
\hline $\mathrm{PCL}^{1}$-and $\mathrm{Eud}^{2} \mathrm{~S} 90 \AA-\mathrm{NC}^{3}$ & $\mathrm{SiO}_{2} /$ spray-drying & A & First report of using spray-drying technique to dry nanocapsule suspensions & 14 \\
\hline PCL-NC and PCL-NS ${ }^{4}$ & $\mathrm{SiO}_{2} /$ spray-drying & A & $\begin{array}{l}\text { The spray-dried powder obtain from nanocapsule suspensions maintained the gastrointestinal } \\
\text { protection against the side effect of the drug }\end{array}$ & 19 \\
\hline PCL-NC and PCL-NS & $\mathrm{SiO}_{2} /$ spray-drying & A & $\begin{array}{l}\text { DSC analyses showed that the sorbitan monostearate is mainly dissolved in the triglyceride } \\
\text { constituting the core of nanocapsules and that this surfactant is heterogeneously dispersed in the } \\
\text { polymer matrix for nanospheres. }\end{array}$ & 15 \\
\hline PCL-NC and PCL-NS & $\mathrm{SiO}_{2} /$ spray-drying & A & A rearrangement of the nanostructure occurred after spray-drying of nanosphere suspensions. & 16 \\
\hline PCL- and Eud S90®- NC and -NS & $\mathrm{SiO}_{2} /$ freeze-drying & A & Successful drying of nanocapsules with the conservation of original properties after rehydration & 21 \\
\hline PCL-NC & $\mathrm{SiO}_{2} /$ spray-drying & A & $\begin{array}{l}\text { Nanospheres are formed as contaminant of nanocapsules by varying the oil and the surfactant } \\
\text { concentrations. }\end{array}$ & 23 \\
\hline PCL- and Eud S100@- NC & $\mathrm{SiO}_{2} /$ spray-drying & $\mathrm{A}$ and $\mathrm{B}$ & The feasibility of preparing controlled nanoparticles-coated drug-loaded inorganic nanoparticles & 29 \\
\hline PCL-NC & $\mathrm{SiO}_{2} /$ spray-drying & A & The powders showed higher chemical stability than the nanocapsule suspensions. & 20 \\
\hline $\begin{array}{l}\text { PCL-, Eud S100®-, Eud RS100®- } \\
\text { and poly(lactide)- NC }\end{array}$ & $\mathrm{SiO}_{2} /$ spray-drying & A & $\begin{array}{l}\text { Nanocapsule spray-dried powders controlled the drug release profile and improved the physical } \\
\text { stability of the product. }\end{array}$ & 25 \\
\hline Eud S100@-NC & $\mathrm{SiO}_{2} /$ spray-drying & $\mathrm{C}$ & $\begin{array}{l}\text { Absence of organic solvent in the coating step. } \\
\text { Nanostrucuture-coated microparticles with excellent yield and encapsulation efficiency }\end{array}$ & 32 \\
\hline PCL-NC & $\mathrm{SiO}_{2} /$ spray-drying & no drug & $\begin{array}{l}\text { The interactions occurring in the feed are directed by hydrogen bounds and they were more } \\
\text { sensitive to the silica concentration than that of nanocapsules. }\end{array}$ & 8 \\
\hline Eud $\mathrm{S} 100 \circledast$ - NC and -NS & $\mathrm{SiO}_{2} /$ spray-drying & $\mathrm{C}$ & $\begin{array}{l}\text { The control of processing variables (inlet temperature and feeding spray rate) allowed obtaining } \\
\text { adequate nanosphere or nanocapsule-coated microparticles }\end{array}$ & 30 \\
\hline PCL-NC & $\mathrm{SiO}_{2} /$ spray-drying & no drug & The concentrations of silicon dioxide and nanocapsules determined the powder characteristics. & 22 \\
\hline PCL-NC & $\begin{array}{l}\text { PVP-K30, mannitol or } \\
\text { lactose/spray-drying }\end{array}$ & B & $\begin{array}{l}\text { Using nanocapsules and lactose, the powder had adequate morphology and ease reconstitution } \\
\text { in water. }\end{array}$ & 24 \\
\hline Eud S100®-NC and -NS & $\mathrm{SiO}_{2} /$ spray-drying & $\mathrm{C}$ & $\begin{array}{l}\text { Nanocapsule-coated microparticles led to a prolonged release and slower transport across Caco- } \\
2 \text { cell monolayers, while the nanosphere-coated microparticles showed a faster release and } \\
\text { Caco-2 transport compared to uncoated microparticles. }\end{array}$ & 33 \\
\hline Eud $\mathrm{S} 100 \circledast-\mathrm{NC}$ and -NS & $\mathrm{SiO}_{2} /$ spray-drying & D & $\begin{array}{l}\text { The drug release showed the gastro-resistance and the efficacy of the new system in reducing } \\
\text { the burst release and in sustaining the drug dissolution profile }\end{array}$ & 35 \\
\hline
\end{tabular}

[1] J. Broadhead, S. K. Edmond Rouan, and C. T. Rhodes, Drug Dev Ind. Pharm. 18, 1169 (1992).

[2] M. I. Ré, Dry. Technol. 24, 433 (2006).

[3] P. Couvreur, C. Dubernet, and F. Puisieux, Eur. J. Pharm. Biopharm. 41, 2 (1995).

[4] P. Couvreur, G. Barratt, E. Fattal, P. Legrand, and C. Vauthier, Crit. Rev. Ther. Drug 1999 (2002).

[5] S. R. Schaffazick; L. L. Freitas, A. R. Pohlmann, and S. S. Guterres, Quim. Nova 26 (2003).

[6] M. D. Coffin and J. W. Mcginity, Pharm. Res.9200 (1992).

[7] B. Magenheim and S. Benita, STP Pharma Sci. 1, 221 (1991).

[8] P. Tewa-Tagne, S. Briancon, and H. Fessi, Int. J. Pharm. 325, 63 (2006).

[9] V. C. F Mosqueira, P. Legrand, H. Pinto-Alphandary, F. Puisieux, and G. Barratt, J. Pharm. Sci. 89, 614, 2000.

[10] R. B. Friedrich, M. C. Fontana, R. C. R. Beck, A. R. Pohlmann, and S. S. Guterres, Quim. Nova (2008), in press.

[11] C. Schmidt and R. Bodmeier, J. Control. Release 57, 115 (1999).

[12] S. Lin and Y. Kao, Pharm. Res. 8, 919 (1991).

[13] Y. Kawashima, T. Iwamoto, T. Niwa, H. Takeuchi, and T. Hino, Int. J. Pharm. 89, 9 (1993).

[14] C. R. Müller, V. L. Bassani, A. R. Pohlmann, C. B. Michalowski, P. R. Petrovick, and S. S. Guterres, Drug Dev. Ind. Pharm. 26, 343, (2000).

[15] C. R. Müller, S. R. Schaffazick, A. R. Pohlmann, L. De Lucca Freitas, N. Pesce Da Silveira, T. Dalla Costa, and S. S. Guterres, Pharmazie 56, 864 (2001).

[16] A. R. Pohlmann, V. Weiss, O. Mertins, N. Pesce Da Silveira, and S. S. Guterres, Eur. J. Pharm. Sci. 16, 305 (2002).

[17] H. Fessi, F. Puisieux, and J. P. Devissaguet, European Patent 0274961, A1 (1988).

[18] D. Quintanar-Guerrero, E. Allémann, H. Fessi, and E. Doelker, Drug Dev. Ind. Pharm. 24, 1113 (1998).

[19] S. S. Guterres, C. R. Müller, A. R. Pohlmann, and T. Dalla Costa, S.T.P. Pharma. Sci. 11, 229 (2001).

[20] C. R. Müller, S. E. Haas, V. L. Bassani, S. S. Guterres, H. Fessi,
M. C. R. Peralba, and A. R. Pohlmann, Quim. Nova 27, 555 (2004).

[21] S. R. Schaffazick, A. R. Pohlmann, T. Dalla Costa, and S. S. Guterres, Eur. J. Pharm. Biopharm. 56, 501 (2003).

[22] P. Tewa-Tagne, G. Degobert, S. Briancon, C. Bordes, J. Y. Gauvrit, P. Lanteri, and H. Fessi, Pharm. Res. 24, 650 (2007).

[23] R. P Raffin, E. S. Obach, G. Mezzalira, A. R. Pohlmann, and S. S. Guterres, Acta Farm Bonaerense 22, 163 (2003).

[24] P. Tewa-Tagne, S. Briancon, and H. Fessi, Eur. J. Pharm. Sci. 30, 124 (2007)

[25] S. R. Schaffazick, A. R. Pohlmann, G. Mezzalira, and S. S. Gutterres, J. Braz. Chem. Soc. 17, 562 (2006).

[26] H. A. Lieberman and L. Lachman, Pharmaceutical Dosage Forms: Tablets (Marcel Decker, New York, 1982).

[27] E. A. Hosny, G. M. El-Mahrouk, and M. W. Gorda, Drug Dev. Ind. Pharm. 24, 661 (1998).

[28] K. Walter, K. and A. von Nieciecki, Arzneimittel-Forsch. 51, 643 (2001).

[29] R. C. R. Beck, A. R. Pohlmann, and S. S. Guterres, J. Microencapsulation 21, 499 (2004).

[30] R. C. R. Beck, S. E. Hass, S. S Guterres, M. I. Ré, E. V. Benvenutti, and A. R. Pohlmann, Quim. Nova 29, 990 (2006).

[31] R. C. R. Beck, M. I. Z. Lionzo, T. M. H. Costa, E. V. Benvenutti, M. I. Ré, M. R. Gallas, A. R. Pohlmann, and S. S Guterres, Braz. J. Chem. Eng. 25, 389 (2008).

[32] R. C. R. Beck, A. R. Pohlmann, E. V. Benvenutti, T. Dalla Costa, and S. S. Guterres, J. Braz. Chem. Soc. 16, 1233 (2005).

[33] R. C. R. Beck, A. R. Pohlmann, C. Hoffmeister, M. R. Gallas, E. Collnot, U. F. Schaefer, S. S. Guterres, and C. M. Lehr, Eur. J. Pharm. Biopharm. 67, 18 (2007).

[34] G. S. Domingues, S. S. Guterres, R. C. R. Beck, and A. R. Pohlmann, Quim. Nova (2008), in press.

[35] L. S. Fonseca, R. P. Silveira, A. M. Deboni, E. V. Benvenutti, T. M. H. Costa, S. S. Guterres, and A. R. Pohlmann, Int. J. Pharm. 358, 292 (2008). 